\title{
Correction to: SICE national survey: current state on the adoption of laparoscopic approach to the treatment of colorectal disease in Italy
}

\author{
Ugo Elmore ${ }^{1,4}$ (D) Andrea Vignali ${ }^{1} \cdot$ Riccardo Rosati $^{1} \cdot$ Andrea Valeri $^{2} \cdot$ Gianfranco Silecchia $^{3} \cdot$ SICE colorectal \\ collaborative group ${ }^{4}$
}

Published online: 15 October 2019

(C) Italian Society of Surgery (SIC) 2019

\section{Correction to: Updates in Surgery (2019) 71:77-81 https://doi.org/10.1007/s13304-018-0606-5}

Page 80, Acknowledgements section: The surname and given name of author Riccardo Brachet Contul was incorrectly published. The correct surname and given name should read as:

Surname: Brachet Contul and Given Name: Riccardo

Publisher's Note Springer Nature remains neutral with regard to jurisdictional claims in published maps and institutional affiliations.

The original article can be found online at https://doi.org/10.1007/ s13304-018-0606-5.

Ugo Elmore

elmore.ugo@hsr.it

1 Department of Surgery, San Raffaele Scientific Institute, University Vita Salute, Milan, Italy

2 Department of Surgery, Ospedale Careggi, Florence, Italy

3 Department of Surgery, University Hospital "La Sapienza", Rome, Italy

4 SICE Collaborative Group, Rome, Italy 